\title{
The Effect of 17-Alpha-Hydroxyprogesterone Caproate on Reducing the Rate of Emergent Cesarean Delivery in Women with Placenta Accrete Spectrum: A Randomized Controlled Study
}

\author{
Hany F. Sallam ${ }^{1, *}$, Nahla W. Shady ${ }^{1}$, Hala M. Ahmed ${ }^{2}$ \\ ${ }^{l}$ Department of obstetrics \& Gynecology, Faculty of medicine, Aswan University, Egypt \\ ${ }^{2}$ Department of Radiology, Faculty of medicine, Aswan University, Egypt
}

*Corresponding Author: Hany F. Sallam, Department of obstetrics \& Gynecology, Faculty of medicine, Aswan University, Egypt, Email: hany.farouk@aswu.edu.eg

\begin{abstract}
Aim: The aim of this study was to evaluate the effect of 17-alpha-hydroxyprogesterone caproate (17OHP-C) for the prevention of preterm nonscheduled delivery in stable women suspected to have placenta accreta spectrum (PAS) at 28-30 weeks gestation.
\end{abstract}

Methods: The study was a randomized open-label clinical trial conducted at a tertiary university hospital
outpatient clinic and some private settings at Aswan governorate, Egypt, between January 2015 and October
2018. We included women who asymptomatic pregnant women with a diagnosed placenta PAS at $28-30$
weeks gestation. They were randomized into two groups: group I (received no treatment), group II (received
an IM. dose of 250 mg 17-alpha-Hydroxyprogesterone caproate once a week). In each group, Follow-up
visits were performed every week then admission was done at 36 weeks at our university hospital. Scheduled
caesarian section was done at completed 37 weeks unless otherwise required.

Results: In our study, 220 patients were randomized to 110 patients in the progesterone group (study group) and 110 patients in (control group). The incidence of emergent CS before 37 weeks was a highly significant decrease in the progesterone group, 41(37.3\%) patients compared to 90(81.8\%) patients in the control group. $p=0.0001$. Hence the incidence of elective CS after 37 weeks was increased in progesterone group 69 (62.7\%) compared with 20(18.2\%) patients in the control group. the $p=0.0001$ The incidence of emergent CS was decreased in progesterone group either with short cervix [32 (76.2\%) patients] or long cervix [9(13.2\%) patients] compared with 45(100\%) patients with the short cervix and 45(69.2\%) patients with long cervix in the control group. however, this reduction was insignificant with a short cervix. $(p=0.066)$ and highly significant with the long cervix. $(p=0.0001)$.

Conclusion: Our findings provided convincing data for prolongation of pregnancy among women with $P A S$, by use of an IM $250 \mathrm{mg}$ 17OHP-C once a week and may decrease the risks of potential emergent nonscheduled delivery seem to support the decision of delayed delivery till maturity especially in low resource countries where the neonatal intensive care facilities are inadequate or not available and perinatal mortality due to prematurity is high.

Keywords: 17-alpha Hydroxyprogesterone caproate, emergent cesarean delivery, placenta accrete spectrum

\section{INTRODUCTION}

The increasing rates of cesarean delivery in recent years have led to an increase in the diagnosis of placenta accrete spectrum (PAS). In 2012 the American College of Obstetricians and Gynecologists stated the incidence to be as high as 1 in 533 deliveries. Now occurring as many as 1 in 272 deliveries $(1,2)$.

The term (PAS) is used to refer to the entire spectrum of conditions including accreta, increta, and percreta as well as to cases of

ARC Journal of Gynecology and Obstetrics clinically "undue adherence of the placenta" to the uterine wall. (2) Prenatal diagnosis of suspected PA has highlighted the need for the physician to decide when and where to deliver.

PAS is associated with numerous adverse maternal and fetal-neonatal complications. Many of these are direct consequences of maternal hemorrhage. Indeed, women with PA are at an increased risk of antepartum vaginal bleeding. The mechanism of bleeding is uncertain but appears to be attributable to the 
separation of the placenta from the underlying decidua resulting from contractions, cervical effacement, cervical dilation, and advancing gestational age. In turn, bleeding is associated with an increased risk of need for blood transfusion, hysterectomy, maternal intensive care unit admission, septicemia, thrombophlebitis, and even maternal death. (3)

The optimal gestational age at delivery for stable women suspected to have PA remains controversial. When morbid adherent placenta previa is suspected, women who receive a scheduled cesarean delivery (CD) experience less blood loss, fewer transfusions, less urologic morbidity, lower admission rates to the intensive care unit, and shorter hospital stay when compared with those requiring emergent cesarean section. So, scheduled preterm delivery is necessary and justified by many obstetricians to avoid serious adverse maternal consequences of the emergency CD. (4) The American College of Obstetricians and Gynecologists (ACOG) has specified that delivery at 34 weeks of gestation may optimize outcomes in stable patients. (6) However, the College and the Society for Maternal-Fetal Medicine (SMFM) also emphasize that delivery timing is individualized because the evidence is limited or inconsistent, with a lack of contemporary controlled trials and large observational studies. $(5,6,7)$ Meanwhile, recent surveys of SMFM and ACOG indicate that a large majority favor delivery at or beyond 36 weeks of gestation rather than earlier in gestation. $(8,9)$

The risks of prematurity must be balanced against the risk of unscheduled delivery in the setting of labor or bleeding. A decision analysis indicated that 34 weeks of gestation is the optimal time for planned delivery of women with PA for fear from unscheduled emergent delivery. (10) However, it is noteworthy that seems to be not cost-effective strategy in low resources developing countries like Egypt. Where the neonatal intensive care facilities are inadequate or not available and perinatal mortality due to prematurity is high, we need to delay the time of delivery without increasing the risk of antepartum hemorrhage (APH) and unscheduled delivery.

Most authors report an increased risk of bleeding with advancing gestation among women with PAS. (11)
ACOG SMFM both recommend the use of 17OHPC to prevent recurrent spontaneous preterm birth. $(5,6)$

We hypothesized that a pharmacological strategy like 17-alpha-Hydroxyprogesterone caproate may improve pregnancy outcomes and may also allow obstetricians to tailor their approach to save delayed scheduled cesarean section women with PA .

The aim of this study to evaluate the role of 17alpha-Hydroxyprogesterone caproate in the prevention of preterm $\mathrm{CD}$ in cases with PAS with avoids of the emergent $\mathrm{CD}$ which affects the maternal outcome and prevents prematurity which affects prenatal outcome especially in low resource countries with inadequate or not available neonatal intensive care facilities.

\section{MATERIALS AND METHODS}

\subsection{Study Type and Settings}

This study was a randomized open-label clinical trial conducted at a tertiary university hospital outpatient clinic and some private settings at Aswan governorate, Egypt, between January 2015 and October 2017. The Institutional Ethical Review Board approved the study, and we obtained a written informed consent from all participants before enrollment

\subsection{Study Participants}

All women attended the outpatient obstetric clinic and diagnosed as PAS were invited to participate in the study. Diagnosis of PAS done at 28:30-week gestation and based on ultrasonographic features which can be seen in form of 1- loss of the retroplacental clear space. 2thinning of the myometrium overlying the placenta- 3-multiple irregular placental lacunae with a "moth-eaten" or "Swiss cheese" appearance of placenta. 4- turbulent blood flow through the lacunae on Doppler velocimetry .

The participated women have entered the screening phase of the study. This phase included history taking [age, parity, number of previous caesarian section (CS) and previous history of preterm labor (PTL)] then measurement of weight and height .

Exclusion criteria were: a 1-medical disorder with pregnancy 2-preeclamptic toxemia 3-fetal anomalies diagnosed by ultrasound 4- patients with cervical cerclage 5- placenta previa without signs of adherence based on ultra-sonographic features. 6- history of antepartum hemorrhage in 
the current pregnancy 7- ruptured membranes 8polyhydramnios 9- multiple gestations 10- fetal growth restriction

\subsection{Randomization}

A statistician prepared computer-generated randomization tables and placed the allocation data in serially numbered closed opaque envelopes. Each envelope had a card noting the intervention type inside. The envelopes were opened only by the principal investigator administering the study medications according to the order of attendance of women. After acceptance of eligible women to participate in the study, we assigned them randomly in a 1:1 ratio to the two arms of the study.

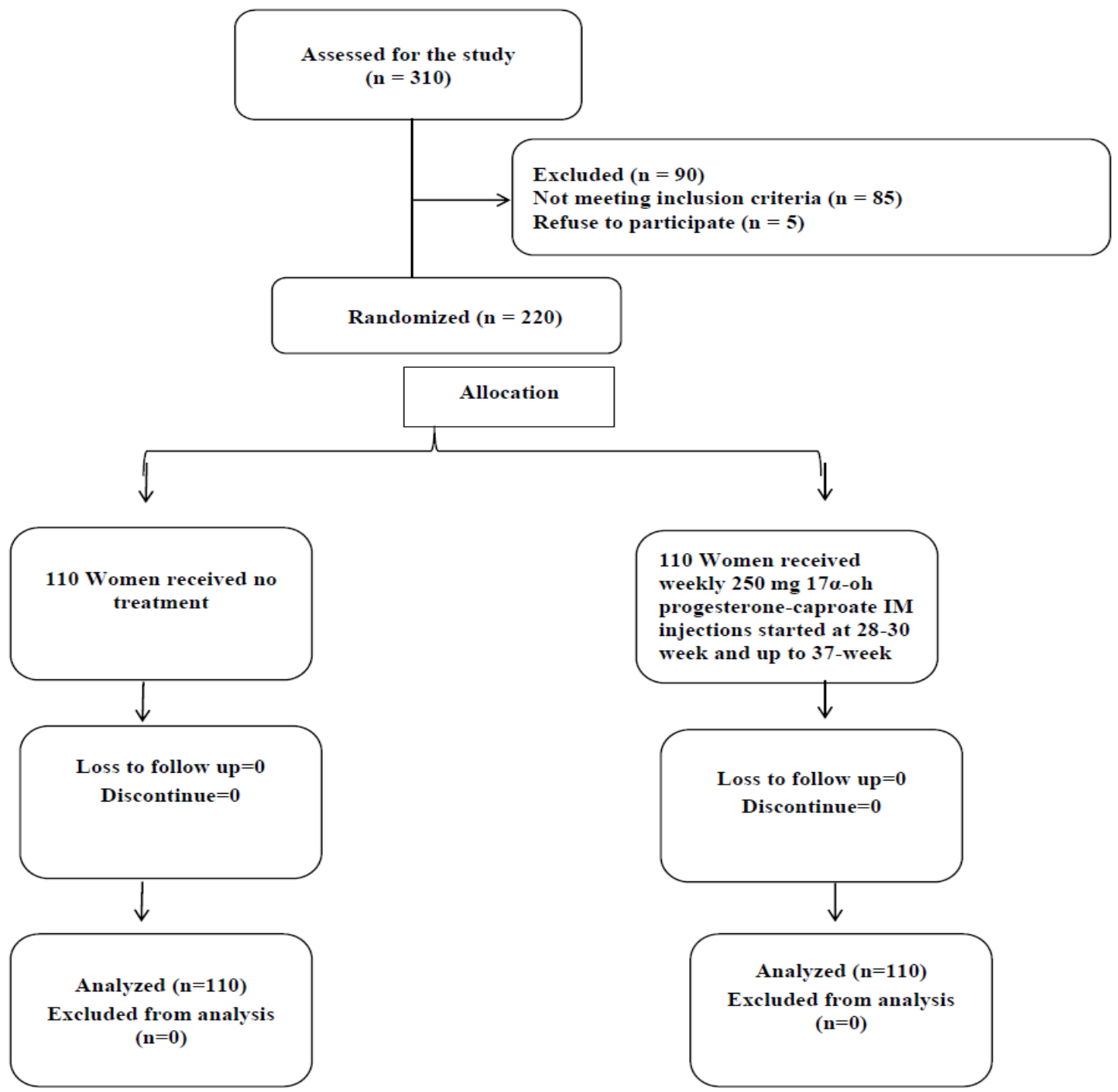

Figure1. Flowchart of the study

\subsection{Intervention}

Three hundred ten patients were invited for the study, eighty-five patients not meeting inclusion criteria and five patients refused to participate therefor two hundred twenty patients were included in the study. All participants underwent a detailed history, general examination, abdominal examination, Transabdominal ultrasound (TAS) and Transvaginal ultrasound (TVS). Cervical length for each patient was measured by TVS using (GE healthcare, Voluson 58) with a multifrequency $5-7.5 \mathrm{MHz}$ transvaginal probe between $28-30$ weeks. A cervical evaluation was performed according to a standardized technique: women were asked to void their bladder before the examination. A true sagittal plane was obtained to visualize the full length of the cervical canal and cervical length was measured three times by placing the calipers on the internal and external OS. The shortest measurement was then recorded.

The eligible women were allocated to one of the two groups: (control group) and study group (progesterone group) received weekly $250 \mathrm{mg}$ 17 alpha-hydroxyprogesterone-caproate (cidolut depot-cid company) intramuscular injections started at 28-30 week and up to 37-weeks' gestation. 


\subsection{Follow-Up Schedule}

Follow-up visits were performed every week then admission was done at 36 weeks at our university hospital. Scheduled caesarian section was done at completed 37 weeks unless otherwise required. If vaginal bleeding occurred prior to the scheduled CS, patients were admitted to the hospital and delivery was decided in accordance with the clinical condition of the patient regardless of gestational age. Induction of fetal lung maturity was carried out by giving $12 \mathrm{mg}$ dexamethasone IM daily for two doses .

The following variables were recorded: gestational age at delivery, the occurrence of peripartum bleeding, emergency CS before 37 weeks due to massive hemorrhage and emergent CS according to cervical length either short cervix $(\leq 2.5 \mathrm{~cm})$ or long cervix $(>2.5 \mathrm{~cm})$

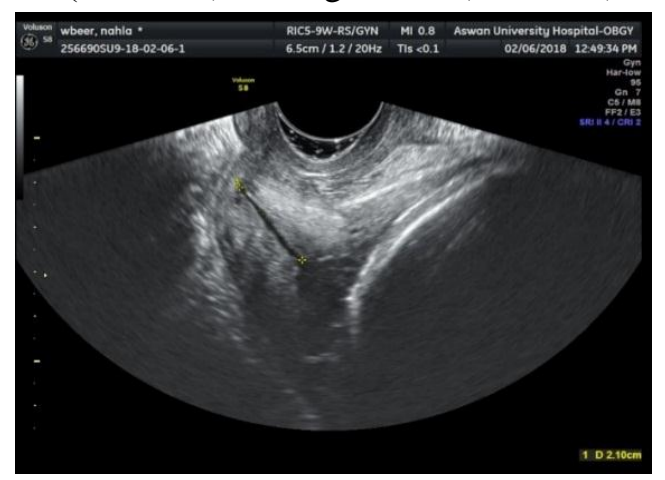

Figure2. Placenta accreta with short cervix $(<2.5$ $\mathrm{cm}$ )
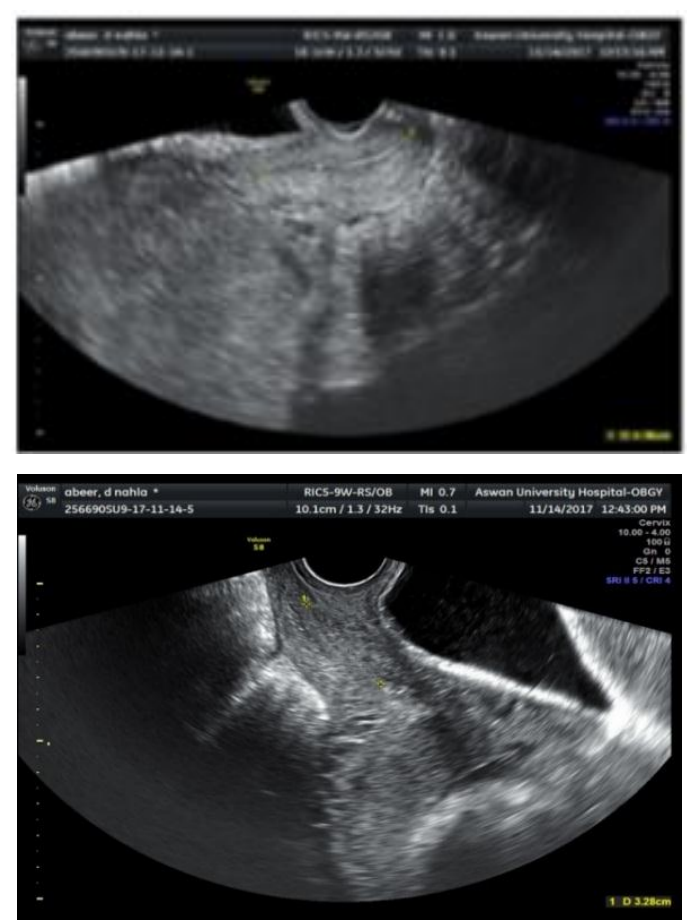

Figure3. Placenta accrete with long cervix (> 2.5 $\mathrm{cm}$ )

ARC Journal of Gynecology and Obstetrics

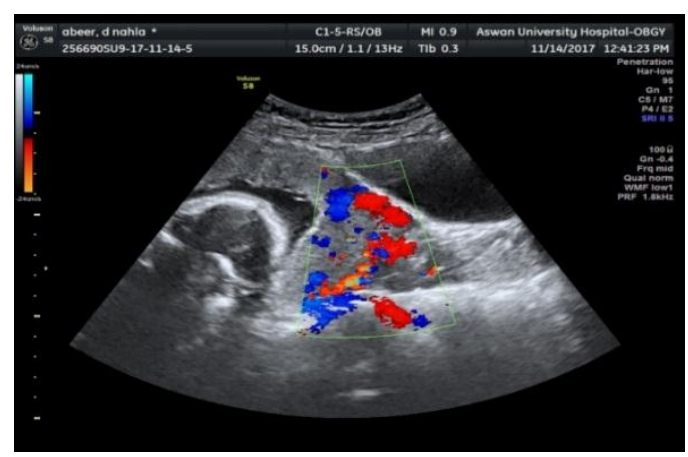

Figure4. Placenta accreta suspected by Doppler US

\subsection{Study Outcomes}

Our study outcome was the incidence of emergent CS before completed 37-weeks' gestation due to antepartum hemorrhage .

\subsection{Statistical analysis}

Data were entered and statistically analyzed using the Statistical Package for Social Sciences (SPSS) version 16. Qualitative data were described as numbers and percentages. Chisquare test was used for comparison between groups. Quantitative data were described as means (SD) after testing for normality by Kolmogorov-Smirnov test. Independent sample t-test was used for comparison between groups. Odds ratios and their 95\% confidence interval were calculated. "p-value $\leq 0.05 "$ was statistically significant.

\section{RESULTS}

Our study, 220 patients were randomized to 110 patients in the progesterone group (study group) and 110 patients in (control group).

There was no significant difference between the two groups with respect to their age, parity, weight, height, number of previous CS and history of preterm labor (PTL). Also, there was no significant difference in relation to their cervical length as the mean cervical length of progesterone group and control group were $(2.9 \pm 0.497)$ and $(2.86 \pm 0.46)$ respectively. $(\mathrm{P}=0.482)$. The incidence of the short cervix was $45(40.9 \%)$ patients in the control group and $42(38.2 \%)$ patients in the progesterone group. $(\mathrm{p}=0.679)$. However, the incidence of the long cervix was $65(59.1 \%)$ patients in the control group and 68(61.8\%) patients in the progesterone group. $(\mathrm{p}=0.679)$

There was a significant increase in gestational age of delivery in the progesterone group $(36.65 \pm 1.12)$ compared with $(35 \pm 1.51)$ in the control group. $\mathrm{p}=0.0001$ (Table 1$)$

Page | 4 
The Effect of 17-Alpha-Hydroxyprogesterone Caproate on Reducing the Rate of Emergent Cesarean Delivery in Women with Placenta Accrete Spectrum: A Randomized Controlled Study

Table1. Demographic criteria of pregnant women in the two groups

\begin{tabular}{|l|l|l|l|}
\hline Parameters & $\begin{array}{l}\text { Control Group } \\
(\mathbf{n = 1 1 0})\end{array}$ & $\begin{array}{l}\text { Progesterone Group } \\
(\mathbf{n = 1 1 0})\end{array}$ & Significance \\
\hline Age (year) & $29.99 \pm 2.611$ & $29.79 \pm 2.634$ & 0.572 \\
\hline Weight (kg) & $78.04 \pm 4.36$ & $77.91 \pm 4.61$ & 0.833 \\
\hline Parity & $3.07 \pm 0.896$ & $2.96 \pm 0.918$ & 0.373 \\
\hline Hight & $165.23 \pm 4.24$ & $164.6 \pm 4.25$ & 0.274 \\
\hline history of (PTL) & $8(7.3)$ & $7(6.4)$ & 0.789 \\
\hline Cervical length & $2.86 \pm 0.46$ & $2.9 \pm 0.497$ & 0.482 \\
\hline Short cervix & $45(40.9)$ & $42(38.2)$ & 0.679 \\
\hline Long cervix & $65(59.1)$ & $68(61.8)$ & 0.679 \\
\hline Initial Hemoglobin $(\%)$ & $9.88 \pm 0.67$ & $9.91 \pm 0.7$ & 0.874 \\
\hline No.of previous $(\mathrm{CS})$ & $2.95 \pm 0.84$ & $2.83 \pm 0.89$ & 0.275 \\
\hline
\end{tabular}

- (PTL)preterm labor, (CS)caesarean section

\# Variables are presented as mean and standard deviation and number (percentage).

-Statistical significance if $p$ value $\leq 0.05$.

The incidence of emergent CS before 37 weeks was a highly significant decrease in progesterone group, 41(37.3\%) patients compared to $90(81.8 \%)$ patients in the control group. $\mathrm{p}=0.0001$. Hence the incidence of elective CS after 37 weeks was increased in progesterone group $69(62.7 \%)$ compared with $20(18.2 \%)$ patients in the control group. $\mathrm{p}=0.0001$

The incidence of emergent CS was decreased in progesterone group either with short cervix [32 $(76.2 \%)$ patients] or long cervix [9(13.2\%) patients] compared with $45(100 \%)$ patients with the short cervix and 45(69.2\%) patients with long cervix in control group. however, this reduction was insignificant with a short cervix. $(\mathrm{p}=0.066)$ and highly significant with the long cervix. $(\mathrm{p}=0.0001)$ (Table2).

Table2. Study outcome in the two groups

\begin{tabular}{|l|l|l|l|}
\hline Variables & $\begin{array}{l}\text { Control Group } \\
(\mathbf{n = 1 1 0})\end{array}$ & $\begin{array}{l}\text { Progesterone Group } \\
(\mathbf{n = 1 1 0})\end{array}$ & Significance \\
\hline Emergent CS(<37 weeks): & $90(81.8)$ & $41(37.3)$ & $0.0001^{*}$ \\
\hline Elective CS(>37 weeks) & $20(18.2)$ & $69(62.7)$ & $0.0001^{*}$ \\
\hline Emergent CS in short cervix $(\leq 2.5 \mathrm{~cm})$ & $45(100)$ & $32(76.2)$ & 0.066 \\
\hline Emergent CS in long cervix $(>2.5 \mathrm{~cm})$ & $45(69.2)$ & $9(13.2)$ & $0.0001^{*}$ \\
\hline APH & $90(81.8)$ & $41(37.3)$ & $0.0001^{*}$ \\
\hline Gestational age at delivery (weeks) & $35.0 \pm 1.51$ & $36.65 \pm 1.12$ & $0.0001^{*}$ \\
\hline
\end{tabular}

(APH) Ante partum hemorrhage

\# Variables are presented as mean and standard deviation and number (percentage).

* Statistical Significant Difference

\section{DISCUSSION}

Most women with PAS will also present with a placenta previa and are therefore at a substantial risk of bleeding and preterm delivery. In the current study, prophylactic use of 17OHP-C effectively increases the gestational age of delivery in the patient diagnosed PAS between 28-30 weeks gestations than patient taken no treatment. Our study is the first one in the evaluation of a novel use of 17OHP-C in the prevention of emergent preterm $\mathrm{CD}$ in a patient with PAS. This prophylactic pharmacotherapy can be very valuable in situations of unavailability or inadequately neonatal intensive care facilities which cannot permit scheduled preterm $\mathrm{CD}$ in our country which was a protocol

ARC Journal of Gynecology and Obstetrics approved to be cost-effective in well-developed countries with good neonatal facilities. (6)

In our study we hypo sized that there are possibilities for use of (17OHP-C) for prevention of emergent delivery in pregnant women with PAS based in its efficacy in prevention of preterm labor which shear some of the pathophysiological etiological factors for emergent delivery with PA, for examples separation of the placenta from the underlying decidua resulting from contractions, cervical effacement, cervical dilation. Many studies found that shorter cervical length (CL) in placenta previa is associated with more bleeding episodes during pregnancy and with earlier delivery due to hemorrhage. (12) 
With suspected PAS, the goals of delayed latepreterm delivery by weekly IM (17OHP-C) are to avoid catastrophic maternal complications (primarily from maternal hemorrhage and its sequelae), to limit the potential for fetal death or compromise from prematurity or maternal hemorrhage, and to avoid an unscheduled delivery performed in a non-ideal location or under suboptimal circumstances. (3) An unscheduled delivery for maternal hemorrhage can result in maternal morbidity and fetal or neonatal hypoxemia or acidemia resulting from maternal hypovolemic shock; delivery in a non ideal location can result in decreased availability of needed critical resources such as blood products, dedicated operating room staff, and surgical specialists. (3)

The risk of massive hemorrhage at delivery or during pregnancy among women with PA is thought to increase with gestational age. $(12,14,15)$ Delivery timing recommendations must weigh the morbidities and risks of hemorrhage, and the risk of emergent delivery due to hemorrhage, including the risks of delivery in a suboptimal location versus scheduled preterm delivery with its prenatal sequelae, there is discordance between delivery timing recommendations and delivery timing in practice. A double-blind, placebo-controlled trial of women with a history of prior spontaneous preterm birth in which women were enrolled at 16-20 weeks of gestation and assigned to receive either weekly injections of $250 \mathrm{mg}$ of 17OHP-C or an inert oil placebo. Injections were continued until delivery or 36 weeks of gestation. The primary outcome was preterm delivery <37 weeks of gestation. Treatment with 17OHP-C significantly reduced the risk of delivery at $<37$ weeks of gestation (36.3\% vs $54.9 \%$; RR: 0.66 ; 95\% CI: 0.54 $0.81)$. There was also a significant reduction in the rate of preterm delivery $<35$ and $<32$ weeks of gestation. However, there were issues of efficacy and safety. (13)

One study observed that when PAS was suspected before delivery, newborns were delivered at early gestational ages (35.6 weeks [33.6-36.9] suspected vs. 37.8 weeks [35.439.9] not suspected, $\mathrm{p}<0.001$ ), were more likely to require ventilator support (24 [28.6\% (95\% CI 18.9-38.2)] suspected vs. 8 [10.8\% (95\% CI 3.7-17.9), $\mathrm{p}=0.006]$ ), and were more likely to be admitted to the neonatal intensive care unit (55 [65.5\% (95\% CI 55.3-75.6)] suspected vs. 25 [33.8\% (95\% CI 23.0-44.6), p
$<0.001]$ ).11 Planned cesarean delivery is a risk factor for respiratory morbidity independent of prematurity; the incidence of respiratory morbidity is significantly higher for the group delivered by cesarean section before the onset of labor $(35.5 / 1,000)$ compared with vaginal delivery $(5.3 / 1,000)$ (OR 6.8; 95\% CI 5.2-8.9). (15)

Three surveys of members of the SMFM (17, 18) and the American College of Obstetricians and Gynecologists (19) suggest that in practice, many US maternal-fetal medicine specialists and obstetricians recommend delivery later than 34-35 weeks. Esakoff et al. (17) surveyed members of SMFM, regarding management practices for women with suspected PAS. The response rate was low at $19.4 \%$. They found that most providers recommend delivery of women with suspected PA at 36 weeks or beyond .

Jolley et al. (18) found that $48.4 \%$ of SMFM members scheduled women with suspected PA for delivery at 36 weeks. The authors conducted a web-based survey prior to the publication of the NICHD recommendation, with a 29\% response rate. Forty-eight percent of respondents reported delivering asymptomatic women with high suspicion for PA at 36 weeks.

In a mailed survey of members of ACOG, with a $51.1 \%$ response rate of whom $85 \%$ were general obstetrician/gynecologists, most $(38.8 \%)$ recommended delivery at 36 weeks. (19)

One multicenter study showed a significant reduction of preterm delivery in women with a history of prior preterm deliveries who were treated with weekly injections of $17 \mathrm{P}(250 \mathrm{mg})$, compared with placebo from weeks 16-20 to week 36 or delivery. (13)

Our study reported a statistically significantly higher gestational age at delivery of the group of women received 17OHP-C in whom cervical length at 28-30 weeks gestation more than 25 $\mathrm{mm}$ compared with the same group receive no treatment. Our study reported that the incidence of emergent CS was decreased in the progesterone group either with a short cervix or long cervix compared with patients with the short cervix and patients with long cervix in the control group. However, this reduction was insignificant with a short cervix and highly significant with the long cervix. This result highlights the role of 17OHP-C in the prevention of cervical ripening and decreases proinflammatory cascade for the beginning of 
parturition but less effective I this cascade already begin. Progesterone may act at the level of the cervix, the addition of progesterone decreased levels of inducible nitric oxide synthase (iNOS) and COX-2, which are associated with cervical ripening. (20) Presentational agents have been found to modulate gene expression in the cervix, postulating another mechanism by which progesterone may prevent preterm births. However, A meta-analysis showed that in women with a mid-trimester short CL, progesterone is associated with a significant reduction in the risk of preterm delivery and neonatal morbidity and mortality, without any deleterious effects on the neurodevelopmental outcome (20)

The strengths of our study include that it was a randomized, clinical trial. The study had its limitations. First, the small sample size of included women may limit the generalizability of our results. Additionally, we did not assess the prenatal outcome of the study groups. Further studies with larger sample size are needed to confirm our results. Moreover, future studies should compare the use of 17OHP-C versus the vaginal progesterone that used widely in low-resource settings.

\section{CONCLUSION}

This study provided convincing data for prolongation of pregnancy among women with PAS, by use of a dose of an IM $250 \mathrm{mg}$ 17OHP$\mathrm{C}$ once a week and may decrease the risks of potential emergent nonscheduled delivery seem to support the decision of delayed delivery till maturity especially in low resource countries where the neonatal intensive care facilities are inadequate or not available and perinatal mortality due to prematurity is high.

\section{REFERENCES}

[1] Mogos MF, Salemi JL, Ashley M, Whiteman VE, Salihu HM. Recent trends in placenta accreta in the United States and its impact on maternal-fetal morbidity and healthcareassociated costs, 1998-2011. J Matern Fetal Neonatal Med.; 29:1077-1082, (2016)

[2] F Gary Cunningham, Kenneth J Leveno, Steven L Bloom, Catherine Y Spong, Jodi S Dashe, et al. William's Obstetrics. (24th edn). pp. 806,(2014)

[3] Crane JM, Van den Hof MC, Dodds L, Armson BA, Liston R. Maternal complications with placenta previa. Am J Perinatol; 17:101$5,(2000)$.
[4] Warshak CR, Ramos GA, Eskander R, Benirschke K, Saenz CC, Kelly TF, et al. Effect of predelivery diagnosis in 99 consecutive cases of placenta accreta. Obstet Gynecol.; 115(1):65-9, (2010).

[5] Placenta accreta. Committee Opinion No. 529. American College of Obstetricians and Gynecologists. ObstetGynecol; 120:20711, (2012).

[6] Publications Committee, Society for MaternalFetal Medicine, Belfort MA. Placenta accreta. Am J ObstetGynecol; 203:430-9(2010).

[7] Shady NW, Sallam HF, Abbas AM. Placenta accreta and emergency cesarean delivery correlates to cervical length and transcervical placental thickness measurement. Int J Reprod Contracept ObstetGynecol.; 6:4808-13,(2017).

[8] Esakoff TF, Handler SJ, Granados JM, Caughey AB. PAMUS: placenta accreta management across the United States. J Matern Fetal Neonatal Med; 25:761-5,(2012)

[9] Wright JD, Silver RM, Bonanno C, Gaddipati S, Lu YS, Simpson LL, et al. Practice patterns and knowledge of obstetricians and gynecologists regarding placenta accreta. J Matern Fetal Neonatal Med; 26:1602-9, (2013).

[10] Robinson BK, Grobman WA. Effectiveness of timing strategies for delivery of individuals with placenta previa and accreta. ObstetGynecol; 116:835-42. (20100.

[11] Bowman Z, Manuck T, Eller A Et al. Risk factors for unscheduled delivery in patients with placenta accreta. Am J Obstet Gynecol.; 210:241. e1-6.(2014)

[12] Spong CY, Mercer BM, D'alton M Et al. Timing of indicated late-preterm and early-term birth. Obstet Gynecol.; 118:323-233. (2011).

[13] Meis P.J., Klebanoff M., Thom E., et al: Prevention of recurrent preterm delivery by 17 alpha-hydroxyprogesterone caproate. N Engl J Med; 348: pp. 2379-2385,(2003).

[14] Al-Khan A, Gupta V, Illsley N Et al. Maternal and fetal outcomes in placenta accreta after institution of team-managed care. Reprod Sci.; 21:761-771. (2014).

[15] Robinson B, Grobman W. Effectiveness of timing strategies for delivery of individuals with placenta previa and accreta. Obstet Gynecol.; 116:835-842.(2010)

[16] Bailit J, Grobman W, Rice M Et al. Morbidly adherent placenta treatments and outcomes. Obstet Gynecol. 2015; 125:683-689.

[17] Esakoff TF, Handler SJ, Granados JM et al. PAMUS: Placenta accreta management across the United States. J Matern Fetal Neonatal Med. 2012; 25:761-765. 
The Effect of 17-Alpha-Hydroxyprogesterone Caproate on Reducing the Rate of Emergent Cesarean Delivery in Women with Placenta Accrete Spectrum: A Randomized Controlled Study

[18] Jolley J, Nageotte M, Wing D et al. Management of placenta accreta: A survey of maternal-fetal medicine practitioners. J Matern Fetal Neonatal Med.; 25:756-760.(2012)

[19] Wright J, Silver RM, Bonanno C et al. Practice patterns and knowledge of obstetricians and gynecologistsregarding placenta accreta. J Matern Fetal Neonatal Med.; 26:16021609.(2013)
[20] Romero R, Nicolaides KH, Conde-Agudelo A, O'Brien JM, Cetingoz E, Da Fonseca E, Creasy GW, Hassan SS. Vaginal progesterone decreases preterm birth $\leq 34$ weeks of gestation in women with a singleton pregnancy and a short cervix: an updated metaanalysis including data from the OPPTIMUM study. Ultrasound ObstetGynecol ; 48: 308-317, (2016).

Citation: Hany F. Sallam, Nahla W. Shady, Hala M. Ahmed, The Effect of 17-Alpha-Hydroxyprogesterone Caproate on Reducing the Rate of Emergent Cesarean Delivery in Women with Placenta Accrete Spectrum: A Randomized Controlled Study. ARC Journal of Gynecology and Obstetrics. 2019; 4(1):1-8. DOI:dx.doi.org/10.20431/2456-0561.0401001.

Copyright: (C) 2019 Authors. This is an open-access article distributed under the terms of the Creative Commons Attribution License, which permits unrestricted use, distribution, and reproduction in any medium, provided the original author and source are credited. 